\title{
DISCLAIMER
}

This report was prepared as an account of work sponsored by an agency of the United States Government. Neither the United States Government nor any agency thereof, nor any of their employees, makes any warranty, express or implied, or assumes any legal liability or responsibility for the accuracy, completeness, or usefulness of any information, apparatus, product, or process disclosed, or represents that its use would not infringe privately owned rights. Reference herein to any specific commercial product, process, or service by trade name, trademark, manufacturer, or otherwise does not necessarily constitute or imply its endorsement, recommendation, or favoring by the United States Government or any agency thereof. The views and opinions of authors expressed herein do not necessarily state or reflect those of the United States Government or any agency thereof.

\section{HYDROCARBONS ASSOCIATED WITH BRINES FROM GEOPRESSURED WELLS}

\author{
Technical Progress Report
}

Second Quarter 1991

Work Performed Under Cooperative Agreement FC07-901012945

\author{
Prepared for the \\ U.S. Department of Energy \\ Under DOE Idaho Field Office \\ Sponsored by the Office of the Assistant Secretary \\ for Conservation and Renewable Energy \\ Office of Industrial Technologies \\ Washington, D.C. \\ Prepared by \\ The University of Southwestern Louisiana (USL)
}


15 July 1991

Quarterly Report No. DE-FC07-90IDI2945-6

Report Period: 1 Apr - 30 Jun 1991

HYDROCARBONS ASSOCIATED WITH BRINES FROM GEOPRESSURED WELLS

THE UNIVERSITY OF SOUTHWESTERN LOUISIANA (USL)

$D E-F C 07-90 I D 12945$

3 Mar 1990 - 31 Dec 1991

Summary of Research Goals:

To determine the concentration of the cryocondensates in fluids of the various USDOE Geopressured wells, function of production volume. The wells will be visited each month that they are operating and samples are to be taken cryogenically during each visit. A gas scrubbing system will continuously sample the gas streams of the wells in the intervals between visit. Collectors, exchanged daily by site personnel, are to be retrieved on each visit.

To correlate the production of the collected compounds with reservoir and well production characteristics.

To develop a harsh environment $\mathrm{pH}$ probe for use in well brines.

Contract Tasks:

Task 1: GAS SCRUBBER S.AMPLES

We have designed and installed a gas scrubbing system at the ZIVL) Pleasant Bayou Well to collect a daily sample of the benzene and toluene components of the cryocondensates. The device is usually simply referred to as the "scrubber". A very small portion of the gas stream is diverted through a pressure and flow control system into a collector. Gas enters the collector at a rate of $10 \mathrm{~mL} / \mathrm{s}$ through a fritted metal gas disperser into a high molecular weight oil. The components of the gas stream are partitioned between the gas and oil phases. Each day the bottle of oil is removed, sealed with a septum and replaced. We are currently using Mobile-1 (TM) for the collection medium since it is relatively inexpensive and contains none of the aromatic compounds of interest. Each month the set of sealed, daily samples are pickedup and returned to our laboratory for gas chroniatographic analysis for benzene and toluene. The daily results are then normalized to the more complete monthly cryogenic analyses. 
During this quarter a total of eighty-four scrubber samples were picked-up on three visits and returned to our laboratory for analyses. The sampling fluid has been changed from Mobil-1 to polyalphaolefins (PAO).

\section{Task 2: DOE WELL SAMPLING}

\section{Background}

The various operational wells are sampled on a monthly basis for the yield of the cryocondensate hydrocarbons. The hydrocarbons of interest are distributed, in the separatcr, between the gas and liquid phases, both phases are sampled to obtain q quantitative analysis. A portion of the gas stream passes $\left(60 \mathrm{ft}^{3}\right.$ over about a three hour period) through a cryogenic system and removes all materials which have partial pressures that allow for their condensation at $-78.5 \mathrm{C}$ : hence the term "cryocondensates" to distinguish them from "condensates", a term commonly used in the oil and gas industry. A second procedure is used to recover the cryocondensate which was not exolved from the brine with the gas. This is accomplished by slowly passing brine from the separator through a coiled tube in an ice/water bath at $0 C$. The lower temperature is used to prevent the loss of the volatile components. In the laboratory the brine is extracted with hexane and the cryocondensate content determined by gas chromatography. From this data the cryocondensate content of the original well brine is determined and the yield corrected to oul field standard conditions: 1 atm pressure and $60 \mathrm{~F}$.

\section{Current Renarting Period}

The only one of the US DOE design wells that was flowing during the reporting period was the Pleasant Bayou \#2. This well was visited and cryogenically sampled as follows:

$\begin{array}{llc}\text { Date } & \begin{array}{l}\text { Flow Rate } \\ \text { (bbls/day) }\end{array} & \begin{array}{c}\text { Cumul. Prod. } \\ \text { (Mbbls) }\end{array} \\ 26 \mathrm{Apr} & 25,230 & 15.8 \\ 23 \mathrm{May} & 24,360 & 16.2 \\ 27 \mathrm{Jun} & 24,260 & 17.0\end{array}$




\section{Background}

The regular cryocondensate samples and the scrubber samples (one for each day since the last visit to the well) referred to above are returned to the laboratory and analyzed by gas chromatography and the yield of these products determined. The monthly cryogenic result is reported in terms of the cumulative brine production. A daily quantitative result is obtained by normalizing the scrubber sample data to the monthly quantitative sample taken as described above.

The results are reported in terms of the production parameters of the well.

\section{Current Reporting Period}

Graphical results for the current reporting period can be found in Appendix A, Figures 1 and 2.

\section{Task 4: HARSH ENVIRONMENT PH PROBE}

\section{Background}

The U.S. Department of Energy has in the past sponsored several attempts to develop a device to measure the $\mathrm{pH}$ in the brine stream of geothermal wells and in other harsh environments. ( for example, see Taylor and Phelan. PNL-3593). As recently as January, 1988, DOE solicited, through its Small Business Innovation Research (SBIR) program. proposals for the development of a similar device. This did not result in funding. Such a device is desirable so as to provide in-situ data for general analysis of brines (and other chemical streams) and in particular to provide data for the understanding of scaling and corrosion.

We became aware of a new device that was being marketed by the CHEMFET Corporation (Bellvue, WA) to measure $p H$ under normal laboratory conditions and were encouraged by Mr. Ray Fortuna (DOE - Wash) to pursue this possibility.. This device was based on the ISFET - the Ion Sensitive Eield Effect Transistor. Under this Task, we are studying the application of these devices under conditions corresponding to those found in typical geopressured brines. In the early stages of the work. CHEM$F E T$. Corp cooperated with us in this effort by donating the ISFETs for tests.

The goal of this task is 10 produce and field test an operational probe on a geopressured well.

\section{Current Reporting Period}

Mr. Jie Chen, who has worked with us over the last year and a 
half, completed all requirements for his Master's thesis entitled: Ion Sensitive Field Effect Transistors Applied to the Measurement of the pH of Brings. Copies of his thesis are available on request.

As reported previously. CHEMFET, Inc. has ceased operations and is in bankruptcy. We have been unable to find any new source from which to obtain ISFETS. Unless this situation changes very soon, we will reluctantly have to abandon this task.

ACTIVITIES NOT COVERED UNDER THE REGULAR TASKS

Dis. Kelley and Meriwether met in Lafayette in June with Dr. Jane Negus-de Whys (INEL), Mr Ken Taylor (DOE-Idaho) and Mr. Bob Creed (DOE-Idaho) to review USL's research activities

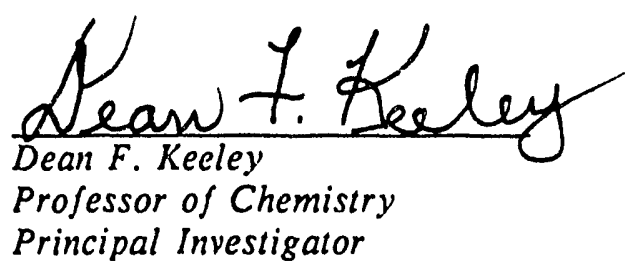

4 
Appendix $A$ 


\section{Cryocondensate, $\mu \mathrm{L} / \mathrm{L}$}

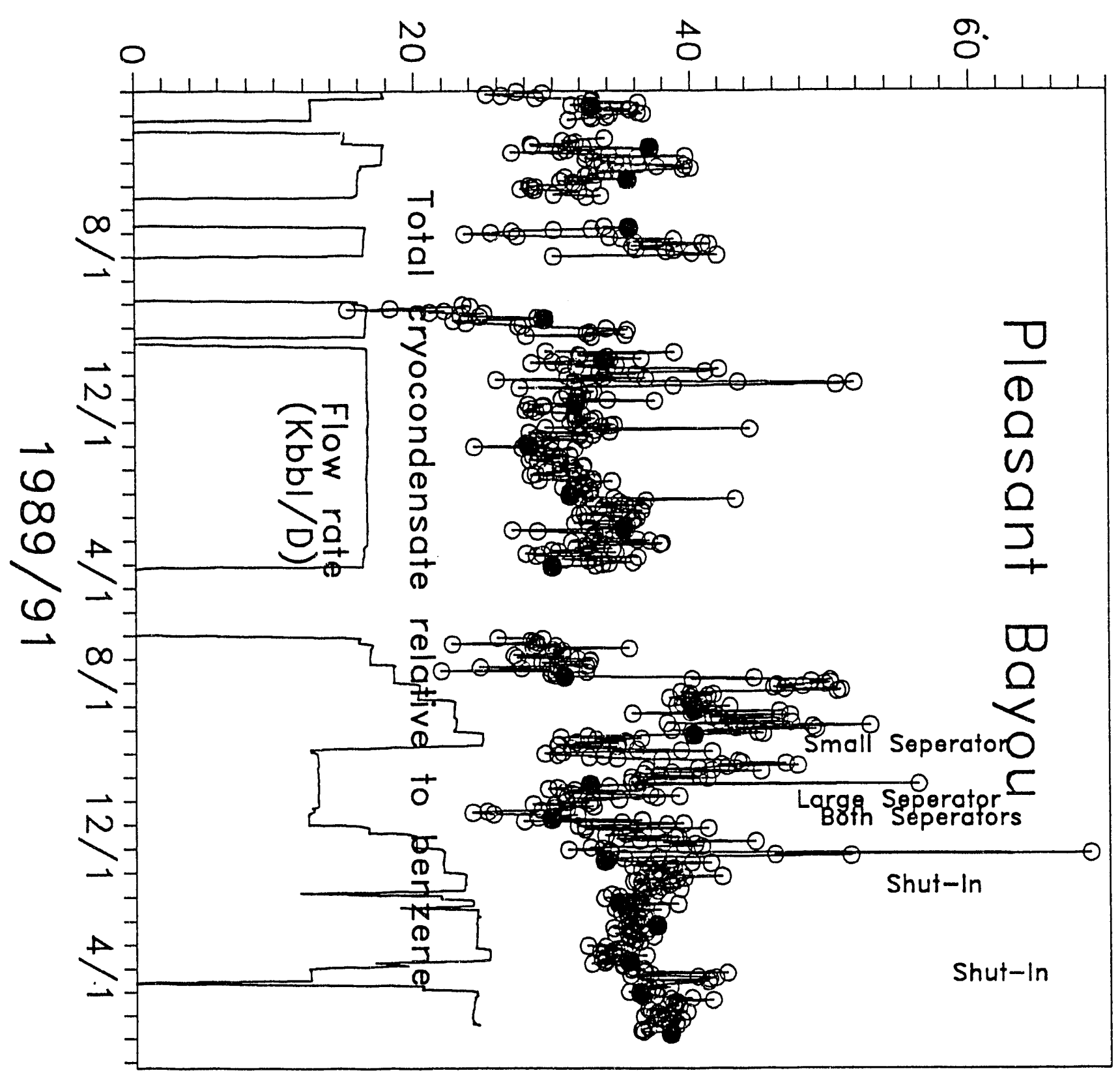




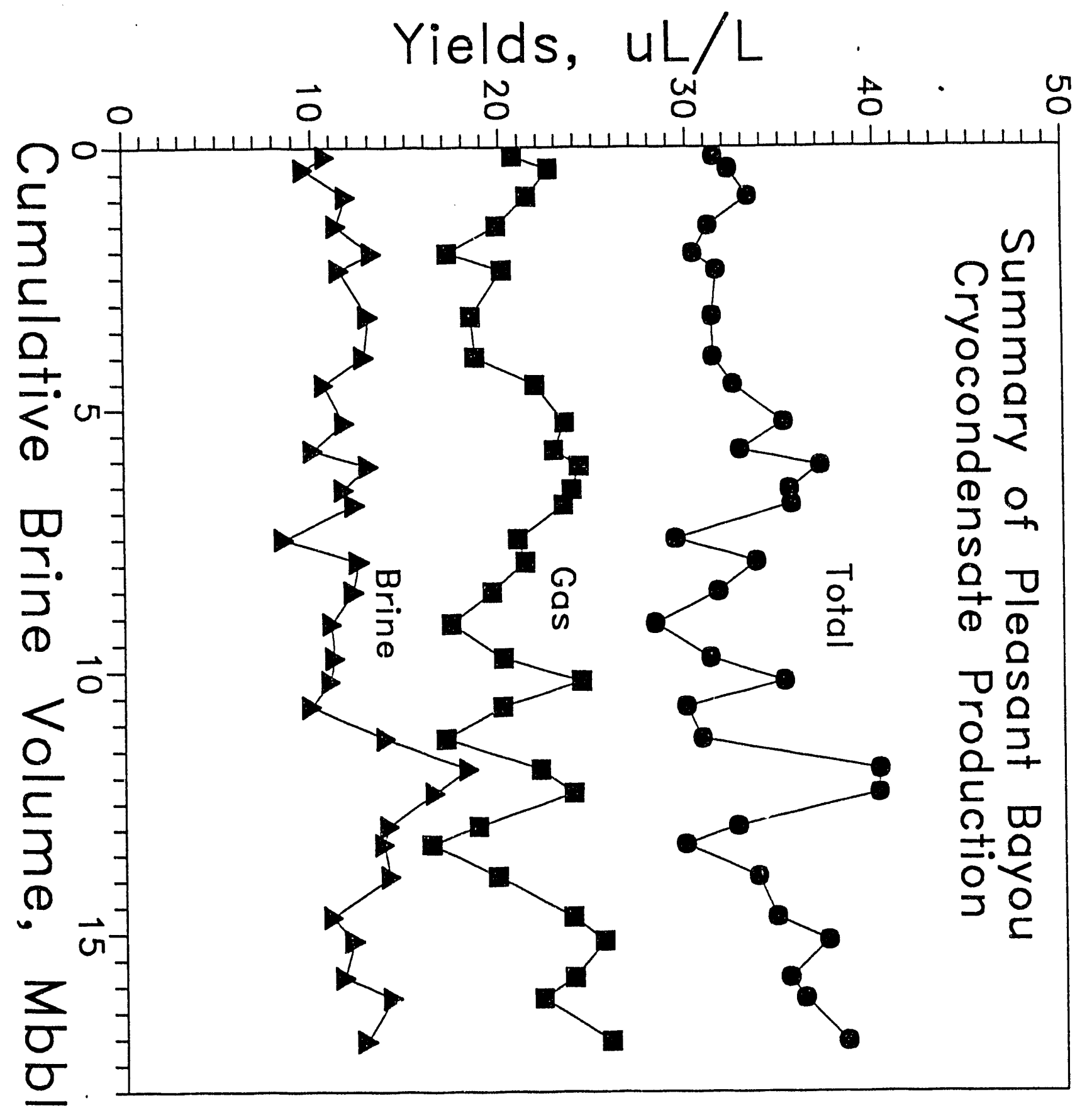



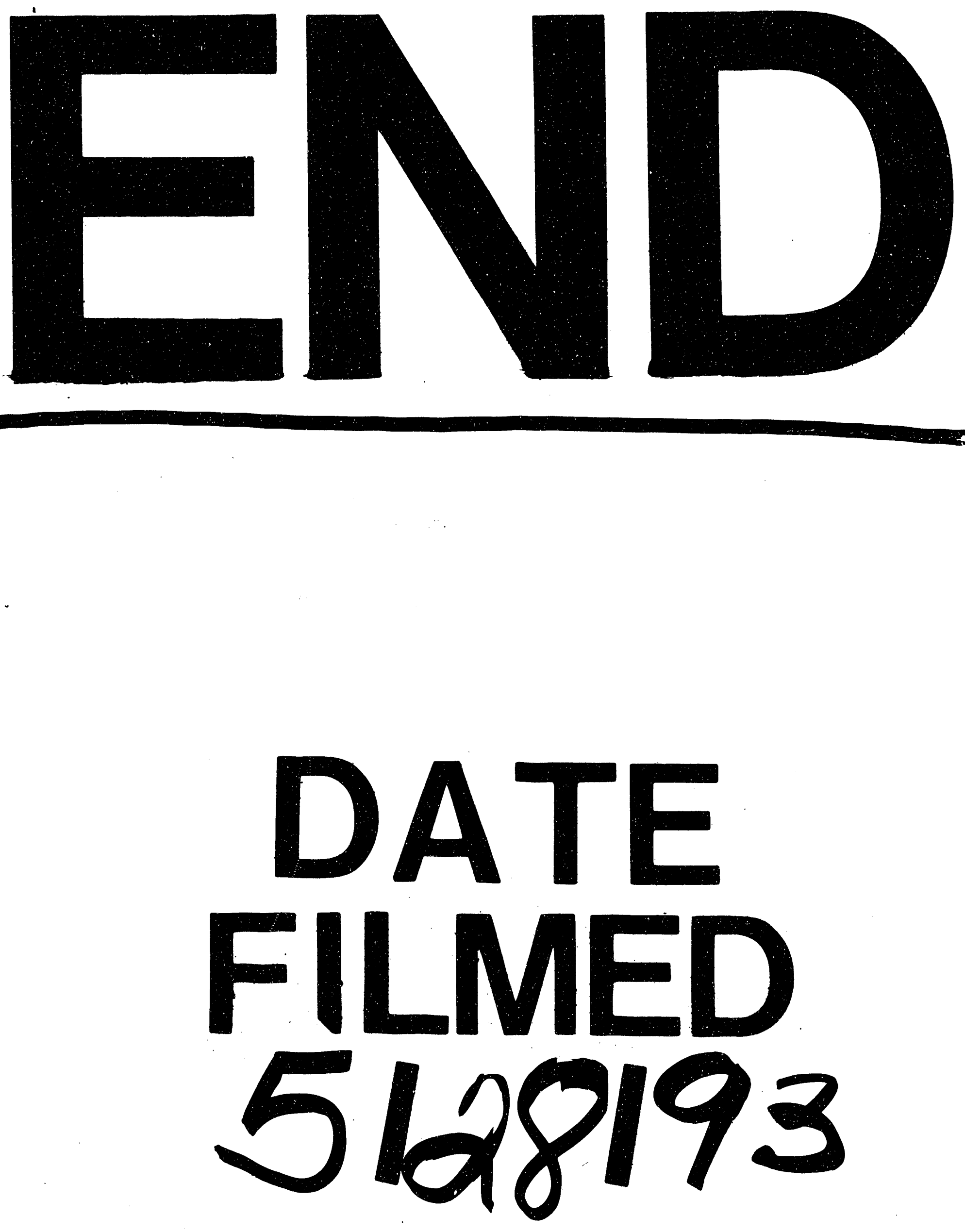
